\title{
Reducing missed orthopedic injuries in the ER
}

$\mathrm{O}$ rthopedic injuries are among the most likely conditions to be missed in emergency departments, family doctors heard during a packed session at the recent Family Medicine Forum in Vancouver, British Columbia.

A major reason these injuries often go undetected is that, in an attempt to "maintain order and expediency," doctors in busy emergency departments often examine $\mathrm{x}$-rays before seeing patients, explained Dr. Vu Kiet Tran, who led the session.

It can be difficult to properly interpret an X-ray, he says, without conducting a physical or learning the patient's medical history. "We have to remind ourselves that we need to speak to the patient and examine the patient first, and then look at the $\mathrm{x}$-ray in the context of the patient, and not vice versa," says Tran, an emergency physician in Richmond Hill, Ontario.

Another problem is the tendency of some emergency physicians not to think about looking for other injuries after finding an initial injury, possibly missing smaller, secondary fractures. "Cognitively, we tend to stop thinking the moment we see one fracture," says Tran. "We think our job is done."

Injuries also go unnoticed when $\mathrm{x}$ rays fail to show fracture lines. By being familiar with other signs of orthopedic injury, however, doctors can still detect these injuries. Tran cites an injured wrist as an example. Physicians who notice misaligned carpal bones on $\mathrm{x}$-rays will detect these injuries even if there are no obvious visual indications of fracture.

To reduce the number of missed orthopedic injuries, emergency physicians should learn about the types of injuries that are missed most often, and be sure to check for them. In fact, having a number of formal checks in place would be a good practice in emergency departments, suggests Tran.

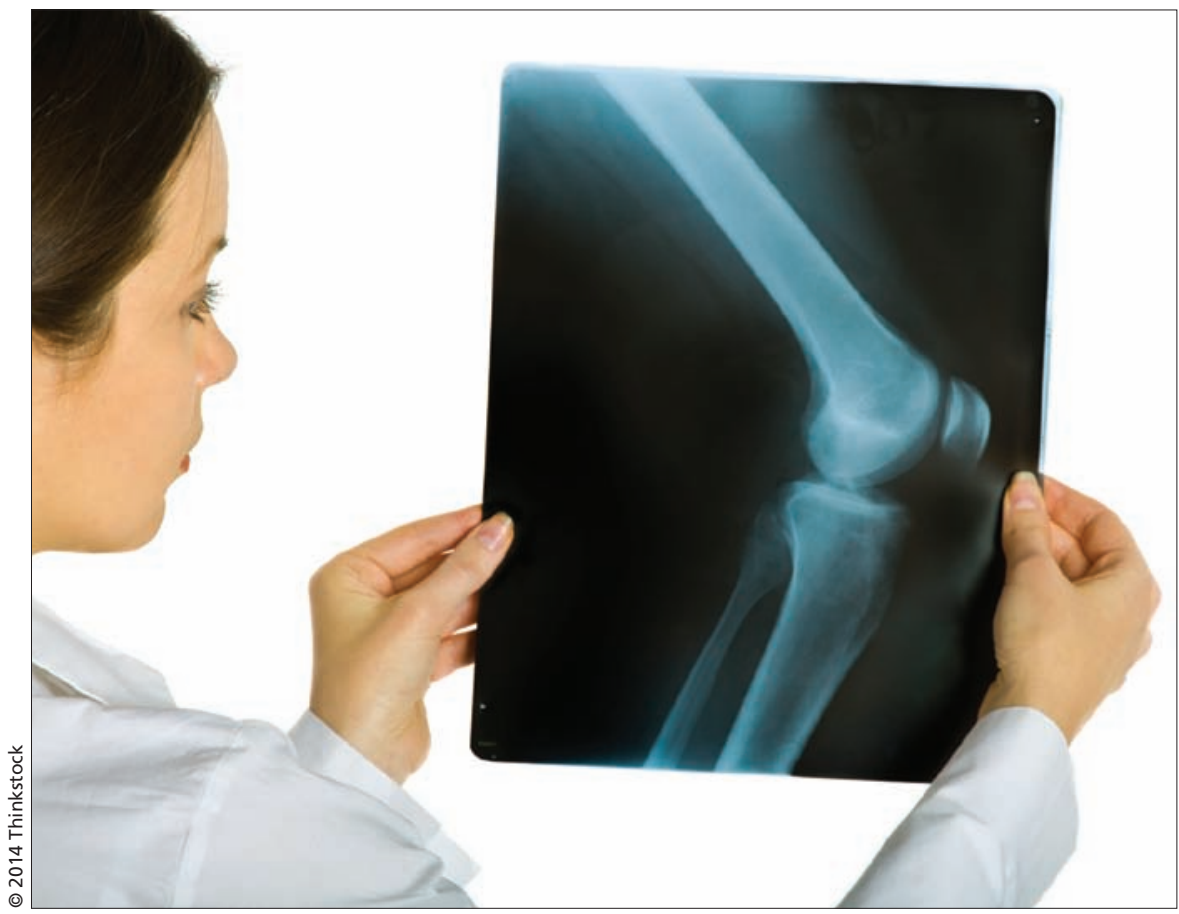

Fractures and other orthopedic injuries may go unnoticed on x-rays if emergency department physicians aren't familiar with nonobvious signs of trauma.

Rapid radiology reporting can be helpful as well. If physicians are able to receive official radiology reports before discharging patients, they can confirm diagnoses and ensure they didn't miss anything.

An electronic medical record system that sends an alert when there are discrepancies between preliminary and subsequent reports would also benefit patients, says Tran. It won't reduce missed injuries, but it means patients with undiagnosed problems can receive follow-up care sooner.

"That way the system is really patient-centric and helps mitigate the long-term complications," says Tran.

Research has shown that missed injuries can eventually result in disabling conditions. Femoral neck stress fractures are commonly missed, for example, and complications include refractures and avascular necrosis $(\mathrm{Am}$
Fam Physician 1998;57:267-74). The most common locations on the body for missed fractures in extremities are the foot $(7.6 \%)$, knee $(6.3 \%)$, elbow (6\%) and hand $(5.4 \%)$, according to one analysis (Acta Radiol 2006;47:710-17).

A study of emergency room errors reported in malpractice claims found that fractures were the most likely diagnosis to be missed, followed by infections and myocardial infarctions (Ann Emerg Med 2007;49:196-205). Missed diagnoses in emergency departments "can have severe consequences and are a major patient safety concern," the paper concluded.

Indeed, the Canadian Medical Protective Association confirms that fractures are among the top 10 complaints physicians face with regulatory colleges. - Catherine Cross, CMAJ

CMAJ 2014. DOI:10.1503/cmaj.109-4674 